\title{
Formal synthesis of (-)-agelastatin A: an iron(II)-mediated cyclization strategy
}

\author{
Daisuke Shigeoka, Takuma Kamon and Takehiko Yoshimitsu*
}

\section{Full Research Paper}

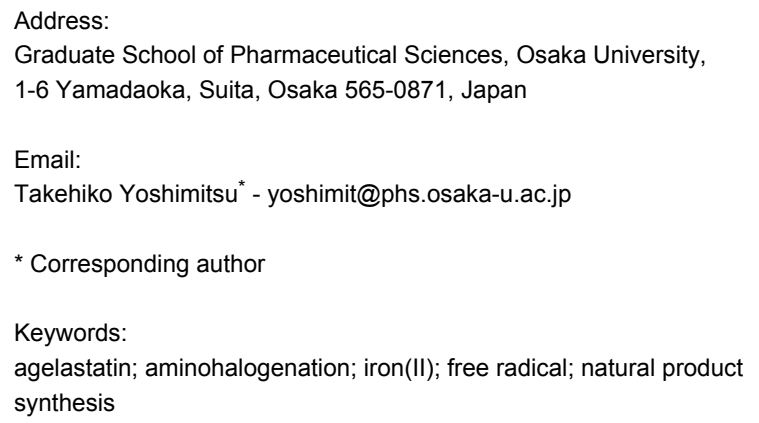

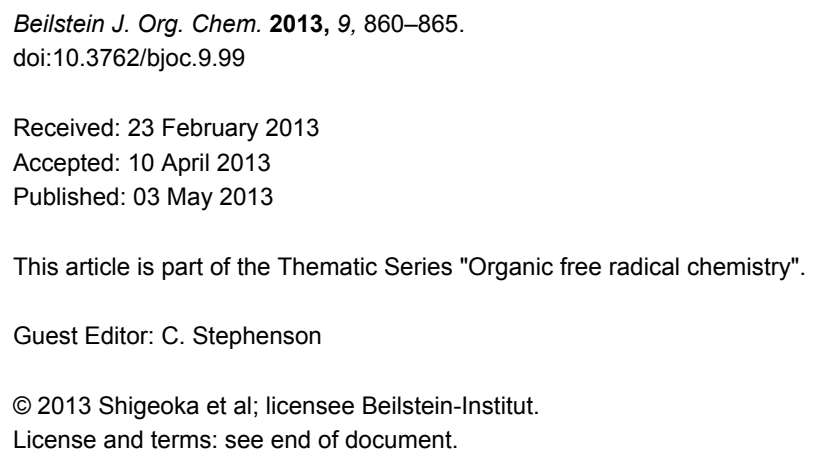

\begin{abstract}
An iron(II)-mediated aminohalogenation of a cyclopentenyl $N$-tosyloxycarbamate provided new access to the key intermediate for the synthesis of (-)-agelastatin A (AA, 1), a potent antiproliferative alkaloid. The present synthetic endeavour offered an insight into the mechanism underlying the iron(II)-mediated aminohalogenation of $N$-tosyloxycarbamate, in which the radical properties of the $\mathrm{N}$-iron intermediates in the redox states were operative.
\end{abstract}

\section{Introduction}

Marine organisms often produce bioactive substances that potentially serve as attractive resources for drug discovery. (-)-Agelastatin A (AA, 1), a cytotoxic alkaloid isolated from marine sponges Agelas dendromorpha and Cymbastela sp., is one such substance, which has drawn considerable attention due to its potential applicability in the development of anticancer agents [1-5]. The intriguing biological activity of $\mathbf{1}$ has stimulated interest in developing various chemical accesses to the natural product [6-25]. Our previous synthetic endeavours have established two approaches to $\mathbf{1}$, in which cyclopentenyl azidoformates $\mathbf{2}$ and $\mathbf{3}$ were utilized as the pivotal intermediates (Scheme 1).
The first-generation strategy employed a stereoselective thermal aziridination of azidoformate $\mathbf{2}$ and a subsequent aziridineopening reaction to establish the vicinal trans nitrogen motif 4 [26]. The second-generation strategy involved the radical aminobromination of azidoformate $\mathbf{3}$ followed by lactamization of the resultant bromide 5a to furnish a tetracyclic compound (structure not shown), which was transformed into the natural product [27]. In the present study, we disclose a new approach to the key intermediate for AA synthesis in which $N$-tosyloxycarbamate 8, a nonhazardous azidoformate surrogate, is transformed into aminohalogenated compounds $\mathbf{5 a}$ and $\mathbf{5 b}$ by $\mathrm{FeBr}_{2} /$ $\mathrm{Bu}_{4} \mathrm{NBr}$ [28,29], $\mathrm{FeCl}_{2} / \mathrm{Bu}_{4} \mathrm{NCl}$, or $\mathrm{FeCl}_{2} / \mathrm{TMSCl}$ [30-35] 


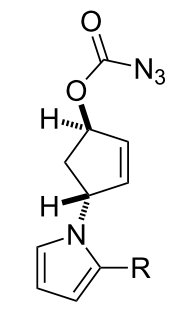

$2 \mathrm{R}=\mathrm{CN}$

$3 \mathrm{R}=\mathrm{CONH}_{2}$ $1^{\text {st }}$-generation [26]

$\Delta$

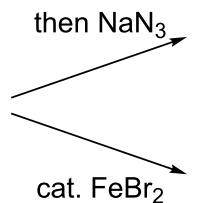

$\mathrm{Bu}_{4} \mathrm{NBr}$

$2^{\text {nd }}$-generation [27]
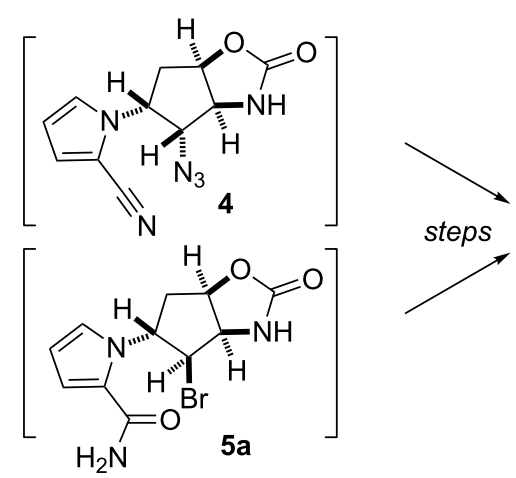

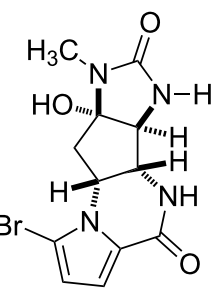

$(-)$-agelastatin A (1)

Scheme 1: Our first- [26] and second-generation [27] approaches to (-)-agelastatin A (1).

(Scheme 2). Moreover, a plausible mechanism of the present iron(II)-mediated aminohalogenation, which is inferred from the unique reactivity of $N$-tosyloxycarbamate 8 with the reagents, is discussed.

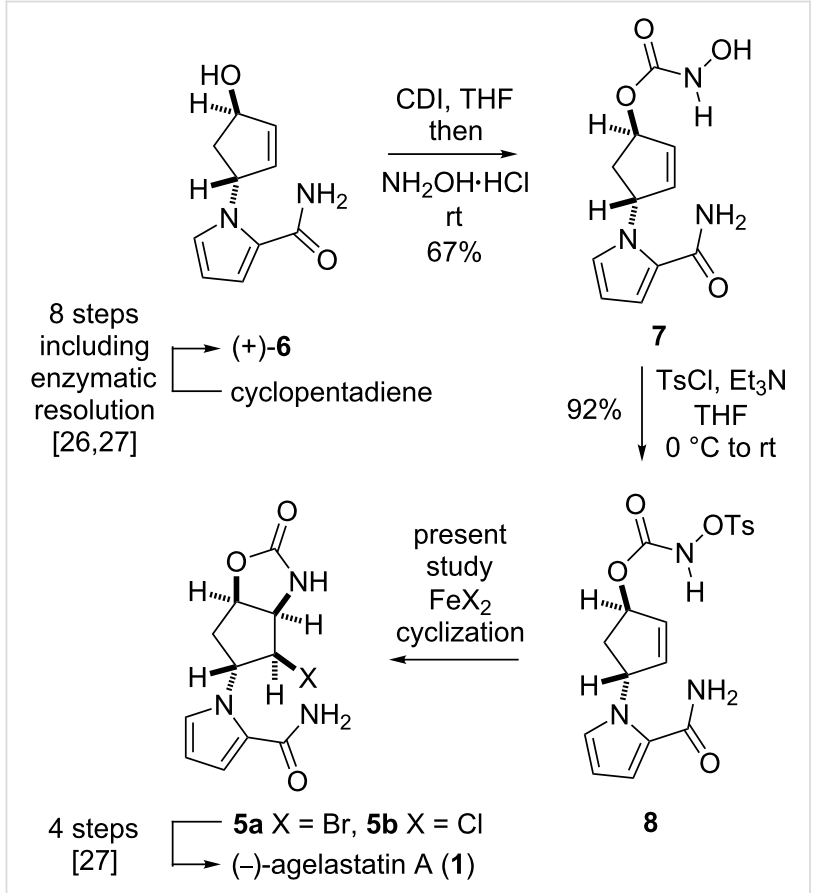

Scheme 2: The present iron(II)-mediated aminohalogenation of $\mathrm{N}$-tosyloxycarbamate $\mathbf{8}$ providing key intermediates $\mathbf{5 a} / \mathbf{5 b}$ for $(-)$-agelastatin A synthesis.

\section{Results and Discussion}

$N$-Tosyloxycarbamate 8 was prepared from alcohol $\mathbf{6}$, which was obtained by a previously reported protocol (Scheme 2) $[26,27]$. Alcohol 6 was first treated with CDI $\left(N, N^{\prime}\right.$-carbonyldiimidazole) and then with hydroxylamine hydrochloric acid salt to afford $N$-hydroxycarbamate 7 in $67 \%$ yield [36]. Thereafter, $\mathrm{N}$-hydroxycarbamate 7 was reacted with $\mathrm{TsCl}$ and triethylamine in THF to furnish $\mathrm{N}$-tosyloxycarbamate $\mathbf{8}$ in $92 \%$ yield.
With this carbamate $\mathbf{8}$, we examined the iron(II)-mediated cyclization under various conditions (Table 1).

The application of $\mathrm{FeBr}_{2}$ ( 0.5 equiv)/ $\mathrm{Bu}_{4} \mathrm{NBr}$ ( 1.5 equiv) in EtOH effected cyclization, but the yield of $\mathbf{5 a}$ was poor due to the concomitant formation of carbamate $9(39 \%)$ and enone 10 $(30 \%)$ (Table 1 , entry 1). This was in marked contrast to the observation that the same reagent system, i.e., $\mathrm{FeBr}_{2}$ ( 0.5 equiv) $/ \mathrm{Bu}_{4} \mathrm{NBr}$ (1.2 equiv), allowed the efficient conversion of azidoformate 3 ( $2 \mathrm{~g}$ scale) in EtOH to afford $\mathbf{5 a}$ in $70 \%$ yield (Scheme 3 ). The distinct yields of the cyclized materials obtained from $\mathrm{N}$-tosyloxycarbamate $\mathbf{8}$ and azidoformate $\mathbf{3}$ suggested the unique reactivity of each substrate towards the iron(II) halide (see below). An aminochlorination reagent system, i.e., $\mathrm{FeCl}_{2}$ ( 0.5 equiv) $/ \mathrm{Bu}_{4} \mathrm{NCl}$ (1.2 equiv) in $\mathrm{EtOH}$, in turn, furnished the corresponding chloride $\mathbf{5 b}$ in $39 \%$ yield as the major product (Table 1, entry 2). Our recent studies on the iron(II)-mediated aminobromination reactions of structurally simple $\mathrm{N}$-tosyloxycarbamates with $\mathrm{FeBr}_{2} / \mathrm{Bu}_{4} \mathrm{NBr}$ revealed significant solvent effects on the product yields [28]. This was also the case in the present study: $\mathrm{FeBr}_{2}(0.5$ equiv $) / \mathrm{Bu}_{4} \mathrm{NBr}$ (1.2 equiv) in $t$ - $\mathrm{BuOH}$ successfully improved the yield of $\mathbf{5 a}$ relative to the reaction in $\mathrm{EtOH}$ (Table 1, entry 3). $\mathrm{FeCl}_{2}$ $(0.5$ equiv $) / \mathrm{Bu}_{4} \mathrm{NCl}$ (1.2 equiv) in $t$ - $\mathrm{BuOH}$ culminated in the highest yield of $\mathbf{5 b}$ among the examined conditions (Table 1, entry 4) However, a reduction of $\mathrm{FeX}_{2}$ loading even in $t$-BuOH led to erosion of the yields of halides $\mathbf{5 a}$ and $\mathbf{5 b}$ with recovery of the substrate (Table 1, entries 5 and 6). With the $\mathrm{FeCl}_{2}$ / TMSCl reagent system [30-35], chloride $\mathbf{5 b}$ was accessible from $N$-tosyloxycarbamate 8 in $29 \%$ yield, along with 9 in $12 \%$ yield (Table 1, entry 7). In this particular case, cyclopentanone derivative $11(16 \%)$ and diethyl ketal 12 (14\%) were produced as well (Figure 1). An additional experiment to elucidate the origin of their formation provided evidence that these byproducts were generated by the intramolecular cyclization of enone 10 with $\mathrm{TMSCl}$ in $\mathrm{EtOH}$, suggesting that the $\mathrm{FeCl}_{2} / \mathrm{TMSCl}$ system also gave enone $\mathbf{1 0}$ in ca. $30 \%$ yield [37]. 
Table 1: Aminohalogenation of $N$-tosyloxycarbamate 8 by iron(II) catalysis.

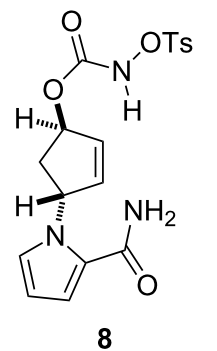

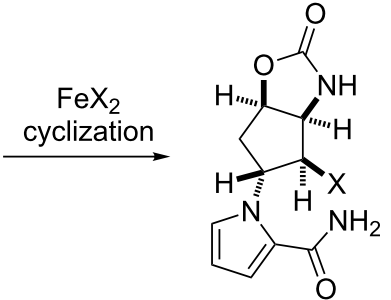

5a $\mathrm{R}=\mathrm{Br}$

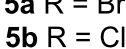<smiles>NC(=O)O[C@H]1C=C[C@@H](n2cccc2C(N)=O)C1</smiles>

9

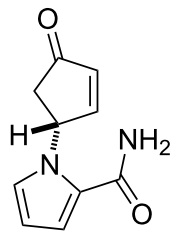

10

\begin{tabular}{ccc}
\hline entry & \multicolumn{1}{c}{ conditions $^{\mathrm{a}}$} & products (\%) \\
\hline 1 & $\mathrm{FeBr}_{2}$ (0.5 equiv), $\mathrm{Bu}{ }_{4} \mathrm{NBr}(1.5$ equiv), $\mathrm{EtOH}, \mathrm{rt}, 1.75 \mathrm{~h}$ & $\mathbf{5 a}(13), \mathbf{9}(39), \mathbf{1 0}(30)$ \\
2 & $\mathrm{FeCl}_{2}\left(0.5\right.$ equiv), $\mathrm{Bu}{ }_{4} \mathrm{NCl}(1.2$ equiv), $\mathrm{EtOH}, \mathrm{rt}, 0.75 \mathrm{~h}$ & $\mathbf{5 b}(39), \mathbf{9}(20), \mathbf{1 0}(19)$ \\
3 & $\mathrm{FeBr}_{2}\left(0.5\right.$ equiv), $\mathrm{Bu}{ }_{4} \mathrm{NBr}(1.2$ equiv), $t-\mathrm{BuOH}, \mathrm{rt}, 0.5 \mathrm{~h}$ & $\mathbf{5 a}(38), \mathbf{9}(22), \mathbf{1 0}(19)$ \\
4 & $\mathrm{FeCl}_{2}\left(0.5\right.$ equiv), $\mathrm{Bu}{ }_{4} \mathrm{NCl}(1.2$ equiv), $t-\mathrm{BuOH}, \mathrm{rt}, 2.5 \mathrm{~h}$ & $\mathbf{5 b}(48), \mathbf{9}(9), \mathbf{1 0}(9)$ \\
5 & $\mathrm{FeBr}_{2}\left(0.2\right.$ equiv), $\mathrm{Bu}{ }_{4} \mathrm{NBr}(1.2$ equiv), $t-\mathrm{BuOH}, \mathrm{rt}, 3.3 \mathrm{~h}$ & $\mathbf{5 a}(25)^{\mathrm{b}}, \mathbf{9}(16), \mathbf{1 0}(5)$ \\
6 & $\mathrm{FeCl}_{2}\left(0.2\right.$ equiv), $\mathrm{Bu}{ }_{4} \mathrm{NCl}(1.2$ equiv), $t-\mathrm{BuOH}, \mathrm{rt}, 3.3 \mathrm{~h}$ & $\mathbf{5 b}(31)^{\mathrm{c}}, \mathbf{9}(9), \mathbf{1 0}(14)$ \\
7 & $\mathrm{FeCl}_{2}\left(0.5\right.$ equiv), $\mathrm{TMSCl}\left(1.5\right.$ equiv), $\mathrm{EtOH}, 0{ }^{\circ} \mathrm{C}$ to rt, $16 \mathrm{~h}$ & $\mathbf{5 b}(29), \mathbf{9}(12)^{\mathrm{d}}$ \\
\hline
\end{tabular}

${ }^{a}$ All reactions were conducted using $20 \mathrm{mg}$ of substrate 8 . ${ }^{b} 22 \%$ of 8 was recovered. ${ }^{c} 35 \%$ of 8 was recovered. ${ }^{d}$ Compounds $11(16 \%)$ and $12(14 \%)$ were obtained.<smiles>CC1C=CC(OC(N)=O)C1C(N)=O</smiles>

3

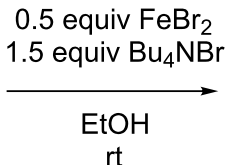

rt

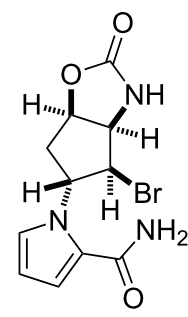

5a $70 \%$<smiles>NC(=O)O[C@H]1C=C[C@H](n2cccc2C(N)=O)C1</smiles>

$916 \%$<smiles>NC(=O)c1cccn1C1C=CC(=O)C1</smiles>

$103 \%$

Scheme 3: Aminohalogenation of azidoformate 3 (2 g scale) under $\mathrm{FeBr}_{2} / \mathrm{Bu}_{4} \mathrm{NBr}$ conditions.

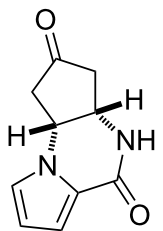

11

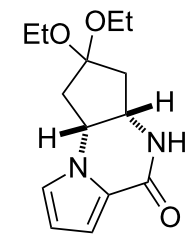

12
Figure 1: Byproducts formed by aminohalogenation of $N$-tosyloxycarbamate 8 with $\mathrm{FeCl}_{2} / \mathrm{TMSCl}$ in $\mathrm{EtOH}$ (see Table 1; entry 7).

The present study on the aminohalogenation reaction of carbamate 8 has inspired mechanistic insights that deserve discussion (Scheme 4). We hypothesize that cyclized material $\mathbf{5 a} / \mathbf{5} \mathbf{b}$, reduced material $\mathbf{9}$, and enone $\mathbf{1 0}$ are generated from an $\mathrm{N}$-iron complex (i) that has free-radical character, as previously proposed in the catalytic cyclization of azidoformates [30,3840]. The contrasting yields obtained from $N$-tosyloxycarbamate 8 and azidoformate 3 under $\mathrm{FeBr}_{2} / \mathrm{Bu}_{4} \mathrm{NBr}$ in $\mathrm{EtOH}$ conditions (see Table 1, entry 1 versus Scheme 3 ) likely originate from the distinct chemical property of the $\mathrm{N}$-iron species (i) generated from each substrate. The possible coordination of tosylate anion to the $\mathrm{N}$-iron after the $\mathrm{N}-\mathrm{O}$ bond cleavage with $\mathrm{FeX}_{2}$ may have affected the electronic and steric characters of intermediate (i), leading to retardation of the subsequent cyclization. Because of the low cyclization rate, the production of reduced carbamate 9 and enone $\mathbf{1 0}$ became pronounced. This is consistent with the observation that the relatively efficient production of cyclized material 5a was observed for azidoformate 3, where $\mathrm{N}$-iron intermediate (i) was free from such interactions. One of the 
other characteristics found in the present transformations was the incomplete consumption of substrate 8 by lowering $\mathrm{FeBr}_{2} /$ $\mathrm{Bu}_{4} \mathrm{NBr}$ loading (e.g., Table 1, entry 5), which, in turn, enabled the efficient conversion of structurally simple $N$-tosyloxycarbamates into the corresponding cyclic aminobromides [28]. This poor conversion under conditions of less $\mathrm{FeX}_{2} / \mathrm{Bu}_{4} \mathrm{NX}$ loading may be attributable to the decrease of the concentration of reactive $\mathrm{FeX}_{2}$ through capture with the polar amide functionality of $\mathbf{8}$.

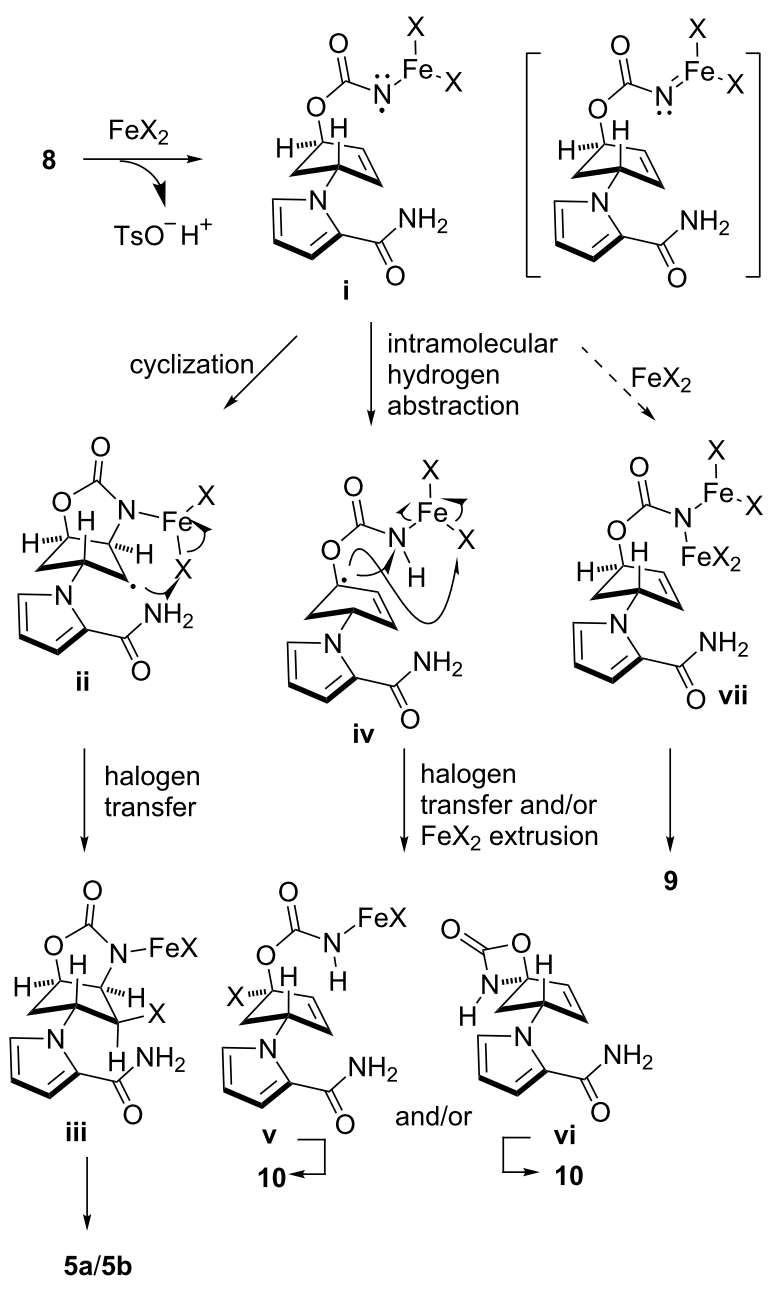

Scheme 4: Plausible reaction pathways in the aminohalogenation of $\mathrm{N}$-tosyloxycarbamate 8 with $\mathrm{FeX}_{2} / \mathrm{Bu}_{4} \mathrm{NX}$.

It is speculated that product 9 may be produced by trapping $\mathrm{N}$-iron complex (i) with another $\mathrm{FeX}_{2}(\mathbf{i} \rightarrow \mathbf{v i i} \rightarrow \mathbf{9})$, whereas enone $\mathbf{1 0}$ is likely to be generated via intramolecular allylic hydrogen abstraction followed by halogen transfer to regenerate iron(II) species $(\mathbf{i} \rightarrow \mathbf{i v} \rightarrow \mathbf{v} \rightarrow \mathbf{1 0})$ and/or by directly releasing $\mathrm{FeX}_{2}(\mathbf{i} \rightarrow \mathbf{i v} \rightarrow \mathbf{v i} \rightarrow \mathbf{1 0})$ [41]. However, it is worth discussing the process for yielding $\mathbf{9}$, which theoretically gener- ates two equivalents of iron(III) species per one equivalent of vii. Given the observation that $\mathrm{FeCl}_{3} / \mathrm{Bu}_{4} \mathrm{NCl}$ gave none of the products shown in Table 1, an iron(III) species possibly generated via the halogen exchange of vii with $\mathrm{Bu}_{4} \mathrm{NX}$, if any, no longer has catalytic activity and thus the catalytic cycle is terminated. Therefore, active $\mathrm{FeX}_{2}$ species should somehow be regenerated to maintain the catalysis. One possible pathway that may account for the production of carbamate 9 through the regeneration of $\mathrm{FeX}_{2}$ species is the intermolecular hydrogen abstraction from substrate $\mathbf{8}$ by $\mathrm{N}$-iron species (i) (Scheme 5). The intermediacy of the intermolecular hydrogen abstraction of $\mathrm{N}$-iron species (i) is supported by the fact that the production of 9 was more pronounced in EtOH having a $\mathrm{C}-\mathrm{H}$ bond $\alpha$ to the oxygen, which likely served as a hydrogen donor (Table 1 , entries 1 and 2). It should be mentioned that reduced material 9 may also be produced by $\mathrm{Bu}_{4} \mathrm{NBr}$ alone as observed in our previous study [28]. To elucidate the contribution of this pathway, compound 8 was treated with $\mathrm{Bu}_{4} \mathrm{NX}$ in $t-\mathrm{BuOH}$. However, no reduced material was obtained within the reaction times depicted in Table 1 [for instance, $0.5 \mathrm{~h}$ stirring for $\mathrm{Bu}_{4} \mathrm{NBr}$ (Table 1, entry 3 ) and $2.5 \mathrm{~h}$ stirring for $\mathrm{Bu}_{4} \mathrm{NCl}$ (Table 1, entry 4)], indicating that the non-iron-mediated process is not significant [42]. Various yields of 9 obtained by loading consistent amounts (1.2-1.5 equiv) of $\mathrm{Bu}_{4} \mathrm{NX}$ salts also indicated the poor contribution of the pathway. Chan and co-workers demonstrated that an iron-imido complex generated from $\mathrm{FeCl}_{2} / \mathrm{PhI}=\mathrm{NTs}$ underwent radical hydrogen abstraction from a formyl group, and combined the resultant radicals (hydrogen atom abstraction/radical rebound pathway) to provide amides $[43,44]$. The involvement of such an iron complex (shown in brackets in Scheme 4) that features radical/ metal-nitrenoid properties can be considered in our reactions. A recent study by Betley and co-workers on high-spin iron-imido complexes generated by the reactions of alkyl azides with $\mathrm{FeCl}_{2}$ bearing dipyrromethene ligands revealed the radical character of the complex $[39,40]$, harmonizing well with our result, which implies the intermediacy of the nitrogen radical species.

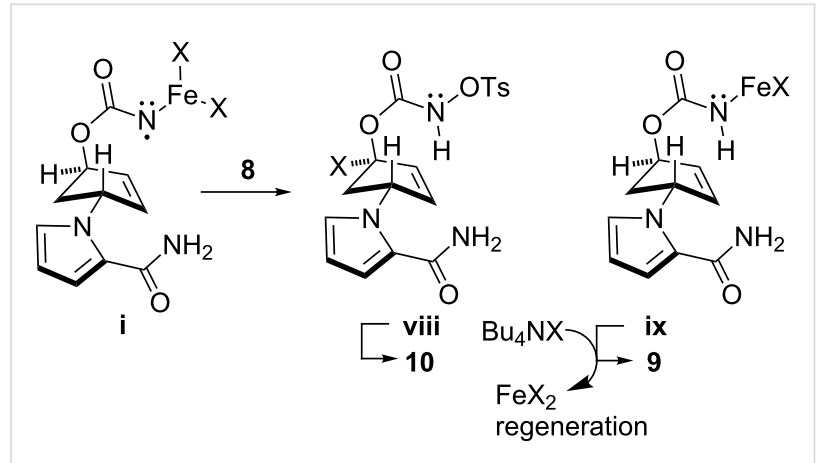

Scheme 5: Plausible reaction pathway to produce compounds 9 and 10. 


\section{Conclusion}

We have developed a new approach to key compounds $\mathbf{5 a} / \mathbf{5 b}$ for (-)-agelastatin A (1) synthesis, which features the iron(II)mediated radical cyclization of $\mathrm{N}$-tosyloxycarbamate, a safe azidoformate surrogate. Although somewhat moderate chemical yields of the compounds were obtained in this study, the elimination of hazardous synthetic processes enables the establishment of more robust strategies to access $\mathbf{1}$. Furthermore, the present study has allowed us to obtain mechanistic insights suggesting that $\mathrm{N}$-iron species (i) has a metal-radical character. Much work is currently being undertaken to comprehend fully the unique properties of the present reactions.

\section{Supporting Information}

\section{Supporting Information File 1}

Experimental procedures, characterization data of new compounds, and ${ }^{1} \mathrm{H} /{ }^{13} \mathrm{C}$ NMR spectra.

[http://www.beilstein-journals.org/bjoc/content/ supplementary/1860-5397-9-99-S1.pdf]

\section{Acknowledgements}

The authors are deeply indebted to Professor Tetsuaki Tanaka for his encouragement. This work was supported by a Special Grant generously provided by the Hoansha Foundation and a Grant-in-Aid for Scientific Research on Innovative Areas [No. 22136006] from the Ministry of Education, Culture, Sports, Science and Technology of Japan (MEXT).

\section{References}

1. D’Ambrosio, M.; Guerriero, A.; Debitus, C.; Ribes, O.; Pusset, J.; Leroy, S.; Pietra, F. J. Chem. Soc., Chem. Commun. 1993, 1305 doi:10.1039/C39930001305

2. Hong, T. W.; Jímenez, D. R.; Molinski, T. F. J. Nat. Prod. 1998, 61, 158. doi:10.1021/np9703813

3. Tilvi, S.; Moriou, C.; Martin, M.-T.; Gallard, J.-F.; Sorres, J.; Patel, K.; Petek, S.; Debitus, C.; Ermolenko, L.; Al-Mourabit, A. J. Nat. Prod. 2010, 73, 720. doi:10.1021/np900539j

4. Pettit, G. R.; Ducki, S.; Herald, D. L.; Doubek, D. L.; Schmidt, J. M.; Chapuis, J.-C. Oncol. Res. 2005, 15, 11.

5. Mason, C. K.; McFarlane, S.; Johnston, P. G.; Crowe, P.; Erwin, P. J.; Domostoj, M. M.; Campbell, F. C.; Manaviazar, S.; Hale, K. J.; El-Tanani, M. Mol. Cancer Ther. 2008, 7, 548 doi:10.1158/1535-7163.MCT-07-2251

6. Stien, D.; Anderson, G. T.; Chase, C. E.; Koh, Y.-H.; Weinreb, S. M. J. Am. Chem. Soc. 1999, 121, 9574. doi:10.1021/ja992487।

7. Feldman, K. S.; Saunders, J. C. J. Am. Chem. Soc. 2002, 124, 9060. doi:10.1021/ja027121e

8. Hale, K. J.; Domostoj, M. M.; Tocher, D. A.; Irving, E.; Scheinmann, F. Org. Lett. 2003, 5, 2927. doi:10.1021/ol035036l

9. Domostoj, M. M.; Irving, E.; Scheinmann, F.; Hale, K. J. Org. Lett. 2004, 6, 2615. doi:10.1021/ol0490476

10. Davis, F. A.; Deng, J. Org. Lett. 2005, 7, 621. doi:10.1021/ol047634I
11. Trost, B. M.; Dong, G. J. Am. Chem. Soc. 2006, 128, 6054. doi:10.1021/ja061105q

12. Ichikawa, Y.; Yamaoka, T.; Nakano, K.; Kotsuki, H. Org. Lett. 2007, 9, 2989. doi:10.1021/ol0709735

13. Dickson, D. P.; Wardrop, D. J. Org. Lett. 2009, 11, 1341 doi:10.1021/ol900133v

14. Wehn, P. M.; Du Bois, J. Angew. Chem., Int. Ed. 2009, 48, 3802. doi:10.1002/anie.200806292

15. Hama, N.; Matsuda, T.; Sato, T.; Chida, N. Org. Lett. 2009, 11, 2687. doi:10.1021/ol900799e

16. Movassaghi, M.; Siegel, D. S.; Han, S. Chem. Sci. 2010, 1, 561. doi:10.1039/c0sc00351d

17. Menjo, Y.; Hamajima, A.; Sasaki, N.; Hamada, Y. Org. Lett. 2011, 13, 5744. doi:10.1021/ol2023054

18. Reyes, J. C. P.; Romo, D. Angew. Chem., Int. Ed. 2012, 51, 6870. doi:10.1002/anie.201200959

19. Kano, T.; Sakamoto, R.; Akakura, M.; Maruoka, K. J. Am. Chem. Soc. 2012, 134, 7516. doi:10.1021/ja301120z

20. Hale, K. J.; Domostoj, M. M.; El-Tanani, M.; Campbell, F. C.; Mason, C. K. In Strategies and Tactics in Organic Synthesis; Harmata, M., Ed.; Academic Press: London, 2005; Vol. 6, p 352. doi:10.1016/S1874-6004(05)80034-6

See for selected reviews of agelastatins and related compounds.

21. Weinreb, S. M. Nat. Prod. Rep. 2007, 24, 931. doi:10.1039/b700206h

22. Dong, G. Pure Appl. Chem. 2010, 82, 2231. doi:10.1351/PAC-CON-10-08-04

23. Young, I. S.; Thornton, P. D.; Thompson, A. Nat. Prod. Rep. 2010, 27, 1801. doi:10.1039/c0np00014k

24. Al-Mourabit, A.; Zancanella, M. A.; Tilvi, S.; Romo, D. Nat. Prod. Rep. 2011, 28, 1229. doi:10.1039/c0np00013b

25. Yamaoka, T.; Ichikawa, Y.; Kotsuki, H. J. Synth. Org. Chem., Jpn. 2012, 70, 615. doi:10.5059/yukigoseikyokaishi.70.615

26. Yoshimitsu, T.; Ino, T.; Tanaka, T. Org. Lett. 2008, 10, 5457. doi:10.1021/ol802225g

27. Yoshimitsu, T.; Ino, T.; Futamura, N.; Kamon, T.; Tanaka, T. Org. Lett. 2009, 11, 3402. doi:10.1021/ol9012684

28. Kamon, T.; Shigeoka, D.; Tanaka, T.; Yoshimitsu, T. Org. Biomol. Chem. 2012, 10, 2363. doi:10.1039/c2ob07190h

29. Nguyen, Q.; Nguyen, T.; Driver, T. G. J. Am. Chem. Soc. 2013, 135, 620. doi:10.1021/ja3113565

See for a recent application of catalytic $\mathrm{FeBr}_{2}$ to $\mathrm{C}-\mathrm{H}$ amination.

30. Bach, T.; Schlummer, B.; Harms, K. Chem. Commun. 2000, 287. doi:10.1039/a909009f

31. Bach, T.; Schlummer, B.; Harms, K. Synlett 2000, 1330. doi:10.1055/s-2000-7129

32. Bach, T.; Schlummer, B.; Harms, K. Chem.-Eur. J. 2001, 7, 2581. doi:10.1002/1521-3765(20010618)7:12<2581::AID-CHEM25810>3.0.C O;2-O

33. Churchill, D. G.; Rojas, C. M. Tetrahedron Lett. 2002, 43, 7225. doi:10.1016/S0040-4039(02)01658-1

34. Bacci, J. P.; Greenman, K. L.; Van Vranken, D. L. J. Org. Chem. 2003, 68, 4955. doi:10.1021/jo0340410

35. Danielec, H.; Klügge, J.; Schlummer, B.; Bach, T. Synthesis 2004, 551. doi:10.1055/s-2005-918500

36. Lebel, H.; Huard, K.; Lectard, S. J. Am. Chem. Soc. 2005, 127, 14198. doi:10.1021/ja0552850 
37. When enone 10 was treated with $\mathrm{TMSCl}$ in $\mathrm{EtOH}$ at room temperature, diethylketal $12(19 \%)$ and ketone $11(10 \%)$ were generated. The TLC analysis of the reaction mixture clearly showed that diethylketal 12 was an initial product, which gradually underwent decomposition to give ketone 11.

38. Protonated cation radical $\mathbf{x}$ is considered to be produced immediately after $\mathrm{N}-\mathrm{O}$ cleavage and may be responsible for the distinct reactivities. However, because of its high acidity, the proton on the carbamoyl nitrogen atom of $\mathbf{x}$ likely dissociates to provide intermediate $\mathbf{i}$.

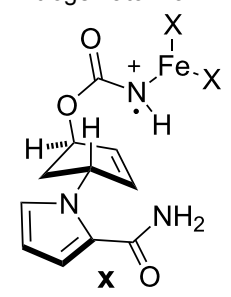

39. King, E. R.; Hennessy, E. T.; Betley, T. A. J. Am. Chem. Soc. 2011, 133, 4917. doi:10.1021/ja110066j

See for recent studies on $\mathrm{C}-\mathrm{H}$ cleavage by $\mathrm{N}$-iron complex showing radical character.

40. Paradine, S. M.; White, M. C. J. Am. Chem. Soc. 2012, 134, 2036. doi:10.1021/ja211600g And references cited therein.

41. It can also be assumed that enone $\mathbf{1 0}$ is generated from intermediate iv via direct fragmentation of an isocyanate and iron(II) halide. We thank one of the referees for suggesting such a possibility.

42. Treatment of substrate 8 with $\mathrm{Bu}_{4} \mathrm{NBr}$ for $2.5 \mathrm{~h}$ gave a small amount of $9(9 \%)$ along with unreacted $8(74 \%)$, whose chemical yields were estimated by ${ }^{1} \mathrm{H}$ NMR analysis of the crude mixture. In contrast, no reduced product 9 was generated at all with $\mathrm{Bu}_{4} \mathrm{NCl}$ after $2.5 \mathrm{~h}$. In this case, after $5.5 \mathrm{~h}$, carbamate 9 was formed in $3 \%$ yield accompanying the recovery of $8(85 \%)$.

43. Ton, T. M. U.; Tejo, C.; Tania, S.; Chang, J. W. W.; Chan, P. W. H. J. Org. Chem. 2011, 76, 4894. doi:10.1021/jo200284a

44. Maestre, L.; Sameera, W. M. C.; Mar Díaz-Requejo, M.; Maseras, F.; Pérez, P. J. J. Am. Chem. Soc. 2013, 135, 1338. doi:10.1021/ja307229e See for a recent discussion on the mechanisms of metal-nitrenide catalysis.

\section{License and Terms}

This is an Open Access article under the terms of the Creative Commons Attribution License (http://creativecommons.org/licenses/by/2.0), which permits unrestricted use, distribution, and reproduction in any medium, provided the original work is properly cited.

The license is subject to the Beilstein Journal of Organic Chemistry terms and conditions: (http://www.beilstein-journals.org/bjoc)

The definitive version of this article is the electronic one which can be found at: doi:10.3762/bjoc.9.99 